\title{
Saneamento básico no Brasil: considerações sobre investimentos e sustentabilidade para 0 século $\mathrm{XXI}^{*}$
}

\author{
Alexandre Bevilacqua Leoneti** \\ Eliana Leão do Prado*** \\ Sonia Valle Walter Borges de Oliveira****
}

Sumário: 1. Introdução; 2. Método; 3 . O setor do saneamento básico no Brasil: desenvolvimento e aspectos legais; 4 . Novas estratégias de gestão; 5 . Considerações finais.

Summary: 1. Introduction; 2. Methods; 3 . The basic sanitation sector in Brazil: evolution and legal issues; 4. New management strategies; 5. Final remarks.

Palavras-chave: saneamento básico; tratamento de esgoto; investimento; sustentabilidade.

KEY WORDs: basic sanitation; sewage treatement; investment; sustainability.

\footnotetext{
* Artigo recebido em jul. 2009 e aceito em nov. 2010. Agradecimentos à Fapesp pelo apoio à pesquisa.

** Bacharel em administração de empresas pela Universidade Paulista, bacharel em matemática aplicada a negócios pela FFCLRP/USP e mestre em administração de organizações pela Fearp/USP. Endereço: Faculdade de Economia, Administração e Contabilidade de Ribeirão Preto (Fearp/USP). Av. Bandeirantes, 3900 - Monte Alegre - CEP 14040-900, Ribeirão Preto, SP, Brasil. E-mail: ableoneti@usp.br.

*** Bacharel em engenharia química pela Universidade de Ribeirão Preto, especialista em informática em educação pela Universidade Federal de Lavras (UFL), especialista em psicopedagogia pela Universidade Federal do Rio de Janeiro (UFRJ). Doutoranda em saúde pública (Eerp/USP). Endereço: Faculdade de Economia, Administração e Contabilidade de Ribeirão Preto (Fearp/USP). Av. Bandeirantes, 3900 - Monte Alegre - CEP 14040-900, Ribeirão Preto, SP, Brasil. E-mail: leprado@ig.com.br.

$* * * *$ Bacharel em arquitetura e urbanismo pela Faculdade de Arquitetura e Urbanismo da Universidade de São Paulo (FAU/USP), mestre em engenharia hidráulica e saneamento pela Escola de Engenharia de São Carlos (Eesc/USP), doutora em administração pela Faculdade de Economia, Administração e Contabilidade (FEA/USP) e livre-docente em administração geral (Fearp/USP). Professora associada da Fearp/USP. Endereço: Faculdade de Economia, Administração e Contabilidade de Ribeirão Preto (Fearp/USP). Av. Bandeirantes, 3900 - Monte Alegre - CEP 14040-900, Ribeirão Preto, SP, Brasil. E-mail: soniavw@terra.com.br.
} 
Desde a década de 1950 até o final do século passado, o investimento em saneamento básico no Brasil ocorreu pontualmente em alguns períodos específicos, com um destaque para as décadas de 1970 e 1980. Em decorrência disso, o Brasil ainda está marcado por uma grande desigualdade e déficit ao acesso, principalmente em relação à coleta e tratamento de esgoto. Atualmente, o setor tem recebido maior atenção governamental e há uma quantidade significativa de recursos a serem investidos. Todavia, faz-se necessário que esses investimentos sejam sustentáveis. Desta forma, o presente trabalho pretendeu, por meio de uma pesquisa descritiva-exploratória, verificar como foram realizados os investimentos em saneamento básico no Brasil, com ênfase no tratamento de esgoto, e discutir como estão sendo disponibilizados os recursos para atender aos aspectos legais aos quais se submetem os municípios neste início de século. Para isto, foram utilizadas, como fontes primárias, entrevistas não estruturadas com técnicos do setor de saneamento e, como fontes secundárias, foram coletadas informações nos sites dos principais órgãos públicos e privados que têm relevância quanto ao saneamento no Brasil. Foram identificadas possíveis falhas no planejamento do setor ao longo destes últimos anos, além de terem sido encontradas evidências que apontam possíveis falhas nas avaliações dos investimentos que estão sendo realizados, não sendo considerada a sustentabilidade dos mesmos. Como contribuição, procurou-se identificar algumas novas formas de gestão em saneamento básico, o que poderá auxiliar os gestores municipais no cumprimento dos seus objetivos.

\section{Basic sanitation sector in Brazil: overview about investments and sustainability for the $21^{\text {st }}$ century}

Since the late 1950th century until the end of the month, the investment in basic sanitation in Brazil occurred occasionally in some specific periods, with an emphasis on the 1970 and 1980. As a result, Brazil is still characterized by great inequality and low access, particularly regarding the collection and sewage treatment. Currently, the sector has received greater government attention and there is a significant amount of resources to be invested. However, it is necessary that these investments are sustainable. Thus, this research sought through a descriptive and exploratory, were performed to see how investment in basic sanitation in Brazil, with emphasis on sewage treatment, and discuss how resources are being made available to meet the legal aspects which are submitted to municipalities beginning of this century. For this purpose, were used as primary sources of unstructured interviews with technicians and sanitation sector as secondary sources, information was collected on the websites of major public and private agencies that have a bearing on the sanitation in Brazil. We identified potential flaws in the planning of the sector over recent years, and have been found evidence that points to possible flaws in the evaluations of the investments being made, not considered their sustainability. As a contribution, we tried to identify some new forms of management in sanitation, which could help municipal managers in achieving its goals. 


\section{Introdução}

A quantidade de água necessária para o desenvolvimento das atividades humanas, tanto no processo de produção de vários tipos de produtos quanto no abastecimento para o consumo de água propriamente dito, vem aumentando significativamente ano após ano no Brasil. Em contraponto, a quantidade de água potável ou de água que possa ser utilizada para satisfazer esses diversos tipos de finalidades não aumentou.

Uma solução para a preservação dessas águas é o investimento em saneamento e no tratamento do esgoto sanitário, que é realizado por meio de estações de tratamento de esgoto que reproduzem, em um menor espaço e tempo, a capacidade de autodepuração dos cursos d'água. As águas recuperadas por essas estações possuem uma grande variedade de aplicações, entre elas: (i) irrigação de campos de esportes, praças etc.; (ii) usos paisagísticos; (iii) descarga de toaletes; (iv) combate a incêndios; (v) lavagem de automóveis; (vi) limpeza de ruas; (vii) usos na construção (Prosab, 2006). Tais alternativas contribuem para a diminuição do uso de água potável para estes fins, além de gerar externalidades positivas sobre a saúde e o meio ambiente (Toneto Junior, 2004:31).

No século passado, desde a década de 1950 até o seu final, o investimento em saneamento básico no Brasil ocorreu pontualmente em alguns períodos específicos, com um destaque para as décadas de 1970 e 1980, quando existia um "predomínio da visão de que avanços nas áreas de abastecimento de água e de esgotamento sanitário nos países em desenvolvimento resultariam na redução das taxas de mortalidade" (Soares, Bernardes e Cordeiro Netto, 2002:1715). Nesse período, foi consolidado o Plano Nacional de Saneamento (Planasa), que deu ênfase ao incremento dos índices de atendimento por sistemas de abastecimento de água, mas que, em contrapartida, não contribuiu para diminuir o déficit de coleta e tratamento de esgoto, o que é ainda verificado atualmente. Até 2006 , apenas $15 \%$ do esgoto sanitário gerado nas regiões urbanas dos municípios do Brasil era tratado (Snis, 2007).

Atualmente, o setor tem recebido maior atenção governamental e existe uma quantidade significativa de recursos a serem investidos. No entanto, esses investimentos devem, além de gerar os benefícios já esperados quanto à melhoria da qualidade da água e dos índices de saúde pública, atender aos padrões mínimos de qualidade, sendo definidos pela legislação específica do setor, com a finalidade de garantir a sustentabilidade dos mesmos.

Nestes últimos anos, as principais normas que regulam o setor de saneamento estão representadas pela Lei 11.445/2007, que estabelece as diretrizes 
nacionais para o saneamento básico, e pela Lei 9.433/1997, referente à Política Nacional de Recursos Hídricos (PNRH). Verificam-se nestas leis algumas exigências para garantir a sustentabilidade dos investimentos em saneamento, mas, segundo Souza, Freitas e Moraes (2007), ainda existe uma predominância de conceitos preventivistas e omissões discursivas, além de visões ambíguas dentro de uma mesma legislação.

Soma-se a isso o fato de que ainda não estão definidas, de maneira clara, as atribuições de cada esfera governamental no que se refere ao saneamento básico. Devido a essa indefinição, União, estados, Distrito Federal e municípios poderiam criar ações redundantes em alguns casos ou se tornar negligentes em outros, deixando a responsabilidade para um dos demais agentes envolvidos. Nesse cenário, a aplicação dos recursos poderia ainda ser realizada sem a adoção de uma visão mais global, que contemple as relações entre esses agentes, prejudicando o planejamento e a eficácia dos recursos aplicados.

Desta forma, o presente trabalho pretendeu, por meio de uma pesquisa descritiva, verificar como foram realizados os investimentos em saneamento básico no Brasil, com ênfase no tratamento de esgoto, e discutir como estão sendo disponibilizados os recursos para atender aos aspectos legais aos quais se submetem os municípios neste início de século. Também se procurou identificar algumas novas formas de gestão em saneamento básico, o que poderá auxiliar os gestores municipais no cumprimento dos seus objetivos.

\section{Método}

O presente estudo pode ser classificado como uma pesquisa descritiva-exploratória. Segundo Gil (1989), os objetivos de uma pesquisa descritiva se concentram em identificar características de determinada população ou objeto de estudo. Já as pesquisas exploratórias são empregadas para "[...] aumentar o entendimento do problema de administração", bem como "[...] reunir informações anteriores sobre o tópico para refinar a questão de pesquisa" (Cooper e Schindler, 2003:222).

Utilizamos fontes primárias e secundárias na coleta de dados. Como fontes primárias, foram feitas entrevistas não estruturadas com técnicos do Departamento de Águas e Energia Elétrica (Daee) de Ribeirão Preto (SP), sobre aspectos do saneamento básico no estado de São Paulo, e com especialistas do Programa de Despoluição de Bacias Hidrográficas (Prodes), da Agência Nacional de Águas (ANA), do Ministério do Meio Ambiente, em Brasília. Como fontes secundárias, foram coletadas informações nos sites dos princi- 
pais órgãos públicos e privados que têm relevância quanto ao saneamento no Brasil, como o Ministério das Cidades, Agência Nacional de Águas (ANA), Banco Nacional de Desenvolvimento (BNDES), Conselho Nacional do Meio Ambiente (Conama), Fundação Nacional da Saúde (Funasa), Instituto Brasileiro de Geografia e Estatística (IBGE), Associação Brasileira das Concessionárias Privadas de Serviços Públicos de Água e Esgoto (Abcon), Associação das Empresas de Saneamento Básico Estaduais (Aesbe) e Associação Nacional dos Serviços Municipais de Saneamento (Assemae). Também foram pesquisadas leis e políticas públicas relacionadas a saneamento no Brasil, além de artigos acadêmicos sobre o tema saneamento.

Os principais descritores buscados na coleta de dados foram: saneamento básico; abastecimento de água; coleta de esgoto; tratamento de esgoto; esgotamento sanitário; resíduos sólidos; investimento em saneamento; universalização do saneamento; setor de saneamento no Brasil; políticas de saneamento.

\section{O setor do saneamento básico no Brasil: desenvolvimento e aspectos legais}

Pelo impacto na qualidade de vida, na saúde, na educação, no trabalho e no ambiente, o saneamento básico envolve a atuação de múltiplos agentes em uma ampla rede institucional. No Brasil, está marcado por uma grande desigualdade e por um grande déficit ao acesso, principalmente em relação à coleta e tratamento de esgoto.

Segundo dados do Sistema Nacional de Informações em Saneamento (Snis, 2007), em 2006, o índice médio de atendimento urbano mostrava valores relativamente elevados, em termos de abastecimento de água, com um índice médio nacional de 93,1\%. Porém, em termos de esgotamento sanitário, o atendimento urbano com coleta era muito escasso, tendo um índice médio nacional de $48,3 \%$, e um índice médio nacional de apenas $32,2 \%$ para o tratamento desse esgoto coletado. Destaca-se que, em relação ao atendimento à população de baixa renda, o índice ainda é mais inadequado, e alcançar uma cobertura mais ampla desse benefício é um grande desafio.

A figura apresenta o total de investimento per capita necessário para universalização do saneamento básico no Brasil e explicita a desigualdade regional causada pela menor capacidade de pagamento da população nas regiões Norte e Nordeste em comparação com as outras regiões. Esse déficit "está intimamente relacionado ao perfil de renda dos consumidores" (Saiani, 2007:263). 
Figura

Investimento necessário para universalização do saneamento no Brasil, 2006

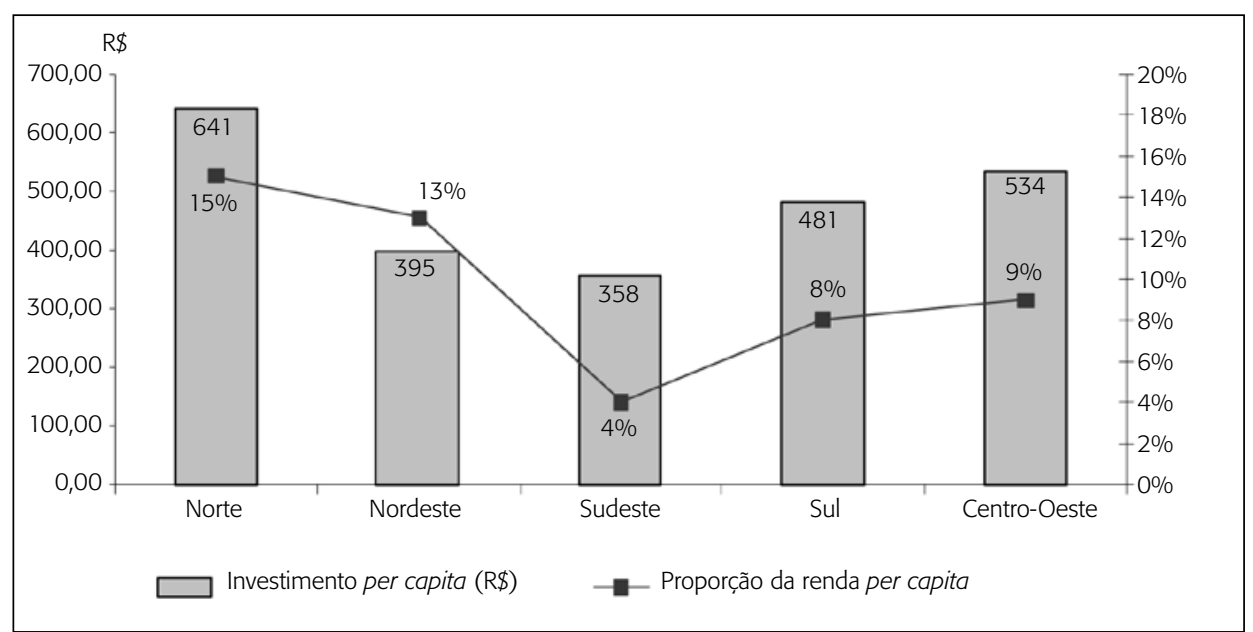

Fonte: Adaptado de Aesbe (2006).

Ainda de acordo com a figura, o Sudeste é a região que necessita de menor investimento per capita, em torno de $\mathrm{R} \$ 358$, enquanto a região Norte necessita de um investimento da ordem de $\mathrm{R} \$ 641$, sendo quase o dobro necessário. Observa-se também que a região Norte possui o maior comprometimento da renda per capita da população com relação ao total necessário a ser investido. Percentuais elevados como este tornariam mais necessária a atuação do Estado com investimentos não reembolsáveis - que não obrigariam o tomador do empréstimo ao pagamento do montante recebido.

Em números absolutos, para que a universalização dos serviços de água e esgoto no Brasil fosse alcançada em 2025, seria necessário que fossem investidos, em média, $\mathrm{R} \$ 11$ bilhões todos os anos, a partir do ano de 2006 até o ano de 2024 (Aesbe, 2006). Todavia, de acordo com os dados do Snis (2007), em 2006, o total de investimentos efetivamente realizados no setor de saneamento brasileiro foi de apenas $\mathrm{R} \$ 4,5$ bilhões (sendo $\mathrm{R} \$ 1,8$ bilhão em coleta e tratamento de esgoto). Este ainda é um reflexo de anos anteriores, quando o investimento foi, em média, $\mathrm{R} \$ 3,9$ bilhões, considerado o período de 2003 a 2006, atualizados para dezembro de 2006, utilizando-se o Índice Nacional de Preços ao Consumidor Amplo (IPCA).

Na tabela 1, observa-se que, no ano de 2000, 47,8\% dos municípios não tinham coleta de esgoto, sendo seus principais receptores os rios e o mar; e, 
dos $52,2 \%$ restantes, que coletam os esgotos, apenas $20,2 \%$ tinham tratamento (UNDP, 2000). Em 2007, de acordo com os dados do Snis (2007), este quadro pouco se alterou, sendo ainda boa parte do esgoto sanitário que é coletado nas cidades despejado in natura em corpos de água ou no solo, principalmente em municípios com população inferior a 30 mil habitantes.

\section{Tabela 1}

Coleta e tratamento de esgoto nos municípios brasileiros no ano 2000

\begin{tabular}{lccc}
\hline & \multicolumn{3}{c}{ Percentual de municípios (\%) } \\
\cline { 2 - 4 } Região & $\begin{array}{c}\text { Com coleta e tratamento } \\
\text { de esgoto }\end{array}$ & $\begin{array}{c}\text { Com coleta e sem } \\
\text { tratamento de esgoto }\end{array}$ & Sem coleta de esgoto \\
\hline Norte & 3,6 & 3,5 & 92,9 \\
Nordeste & 13,3 & 29,6 & 57,1 \\
Sudeste & 33,1 & 59,8 & 7,1 \\
Sul & 21,7 & 17,2 & 61,1 \\
Centro-Oeste & 12,3 & 5,6 & 82,1 \\
Brasil (total) & 20,2 & 32,0 & 47,8 \\
\hline
\end{tabular}

Fonte: UNDP (2000).

Este déficit de acesso foi ocasionado, em grande parte, pela "fragmentação das responsabilidades e dos recursos federais, indefinições regulatórias e irregularidades contratuais" (Saiani, 2007:262). Estes problemas dificultam a qualidade dos investimentos e a participação privada no setor de saneamento. Segundo Toneto Junior (2004:178), pode-se afirmar que, apesar de apresentar praticamente todas as características dos demais setores de infraestrutura, "o setor de saneamento básico é o que ainda apresenta a menor participação do setor privado". Segundo os dados da Associação das Empresas de Saneamento Básico Estaduais (Aesbe, 2006), em 2006, mais de 95\% dos serviços de saneamento eram realizados por organizações do setor público, ou seja, menos de $5 \%$ dos serviços de saneamento eram realizados por empresas do setor privado.

A pequena participação do setor privado e a limitação do endividamento público, imposta às gestões municipais pela Lei Complementar no 101, de 4 de maio de 2000, denominada como Lei de Responsabilidade Fiscal, ainda são os principais fatores da escassez de investimentos e, consequentemente, da baixa eficiência do setor de saneamento no Brasil. Até os dias de hoje, os poucos investimentos realizados foram, em grande parte, facilitados por pla- 
nos específicos para o setor, como o Plano Nacional de Saneamento (Planasa), que incentivou a criação e o fortalecimento das concessionárias municipais, e pelos investimentos de bancos públicos, como a Caixa Federal e o Banco do Desenvolvimento Nacional (BNDES, 2008b).

$\mathrm{Na}$ década de 1990 foram implantados alguns programas federais de apoio ao saneamento com financiamentos do Orçamento Geral da União (OGU), Banco Interamericano de Desenvolvimento (BID), Banco Mundial (Bird), Banco Nacional do Desenvolvimento Econômico e Social (BNDES), Financiadora de Estudos e Projetos (Finep), Conselho Nacional de Pesquisas (CNPq) e Coordenação de Aperfeiçoamento de Pessoal de Nível Superior (Capes). Essas informações estão apresentadas no quadro.

Quadro

Principais programas federais em saneamento na década de 1990

\begin{tabular}{|c|c|c|c|}
\hline Programa & Período & Financiamento & Beneficiário/Desdobramentos \\
\hline Pronurb & 1990-1994 & FGTS e contrapartida & $\begin{array}{l}\text { População urbana em geral, com } \\
\text { prioridade à baixa renda }\end{array}$ \\
\hline Pró-Saneamento & 1995 & FGTS e contrapartida & $\begin{array}{l}\text { Preponderantemente áreas com } \\
\text { famílias com renda de até } 12 \mathrm{s.m} \text {. }\end{array}$ \\
\hline Pass & 1996 & $\begin{array}{l}\text { Orçamento Geral da União } \\
\text { (OGU) e contrapartida, } \\
\text { Banco Interamericano de } \\
\text { Desenvolvimento (BID) e } \\
\text { Banco Mundial (Bird) }\end{array}$ & $\begin{array}{l}\text { População de baixa renda } \\
\text { em municípios com maior } \\
\text { concentração de pobreza }\end{array}$ \\
\hline Prosege & 1992-1999 & BID e contrapartida & $\begin{array}{l}\text { População de baixa renda, } \\
\text { privilegiando comunidades com } \\
\text { renda de até } 7 \text { s.m. }\end{array}$ \\
\hline Funasa-SB & & OGU e contrapartida & $\begin{array}{l}\text { Apoio técnico e financeiro no } \\
\text { desenvolvimento de ações com } \\
\text { base em critérios epidemiológicos } \\
\text { e sociais }\end{array}$ \\
\hline PMSS I & 1992-2000 & Bird e contrapartida & $\begin{array}{l}\text { Estudos e assistência técnica } \\
\text { aos estados e municípios em } \\
\text { âmbito nacional; investimentos } \\
\text { em modernização empresarial e } \\
\text { aumento de cobertura dirigidos à } \\
\text { Casan, Embasa e Sanesul }\end{array}$ \\
\hline PMSS II & 1998-2004 & Bird e contrapartida & $\begin{array}{l}\text { Passa a financiar companhias do } \\
\text { Norte, Nordeste e Centro-Oeste } \\
\text { e estudos de desenvolvimento } \\
\text { institucional }\end{array}$ \\
\hline
\end{tabular}




\begin{tabular}{|c|c|c|c|}
\hline Programa & Período & Financiamento & Beneficiário/Desdobramentos \\
\hline PNCDA & 1997 & OGU e contrapartida & $\begin{array}{l}\text { Uso racional de água em } \\
\text { prestadores de serviço de } \\
\text { saneamento, fornecedores e } \\
\text { segmentos de usuários }\end{array}$ \\
\hline FCP/SAN & 1998 & FGTS, BNDES e contrapartida & $\begin{array}{l}\text { Concessionários privados em } \\
\text { empreendimentos de ampliação } \\
\text { de cobertura em áreas com renda } \\
\text { de até } 12 \mathrm{~s} . \mathrm{m} \text {. }\end{array}$ \\
\hline Propar & 1998 & BNDES & $\begin{array}{l}\text { Estados, municípios e } \\
\text { concessionários contratando } \\
\text { consultoria para viabilização de } \\
\text { parceria público-privada }\end{array}$ \\
\hline Prosab & 1996 & Finep, CNPq, Capes & $\begin{array}{l}\text { Desenvolvimento de pesquisa } \\
\text { em tecnologia de saneamento } \\
\text { ambiental }\end{array}$ \\
\hline
\end{tabular}

Fonte: Turolla (2002).

Atualmente, por meio de políticas de saneamento ambiental e o afrouxamento das regras de acesso ao setor privado, o setor de saneamento tem recebido considerável atenção e incremento de investimentos tanto do setor privado, viabilizado pelas parcerias público-privadas (PPPs) e por recursos próprios, quanto do setor público, por meio de recursos do Fundo de Garantia do Tempo de Serviço (FGTS), do Fundo de Amparo ao Trabalhador (FAT), do Orçamento Geral da União (OGU) e de programas como o Programa de Despoluição de Bacias Hidrográficas (Prodes), que paga aos municípios pelo esgoto efetivamente tratado (ANA, 2008).

Para viabilizar os investimentos no âmbito governamental, foi estabelecida por meio da Lei 11.445, de 5 de janeiro de 2007, a Política Federal de Saneamento Básico, que em seu capítulo IX orienta a ação do governo federal por meio da definição de um conjunto amplo de diretrizes, objetivos e metas para a universalização e definição de programas, ações e estratégias para investimentos no setor (Brasil, 2006). Os aspectos ambientais, que complementam essa legislação, são tratados pelas resoluções elaboradas no âmbito das agências de regulamentação, tais como a Resolução no 357 do Conselho Nacional do Meio Ambiente (Conama, 2005), que dispõe sobre a classificação dos corpos de água e diretrizes ambientais para o seu enquadramento, bem como estabelece as condições e padrões de lançamento de efluentes. Essa re- 
solução sofreu ajustes com a Resolução no 397 , de 2008, como a exclusão do parâmetro nitrogênio amoniacal total em sistemas de tratamento de esgotos sanitários (Conama, 2008).

O Conselho das Cidades também aprovou em 3 de dezembro de 2008, por meio da Resolução Recomendada oㅡ 62, o Pacto pelo Saneamento Básico, que marcou o início da elaboração do Plano Nacional de Saneamento Básico (Plansab). Esse pacto, fruto de ampla discussão com as principais entidades representativas do setor, representa o compromisso com a elaboração do plano que visa estabelecer um ambiente de confiança e entendimento no alcance dos seus objetivos e metas (Brasil, 2008).

Consta como um dos principais objetivos deste pacto que, quanto à gestão dos serviços de saneamento, o Plansab

[...] deverá buscar o desenvolvimento de mecanismos de gestão dos serviços e incentivar o desenvolvimento de modelos alternativos de gestão que permitam alcançar níveis crescentes de eficiência e eficácia e a sustentabilidade social, ambiental, econômica e financeira do saneamento básico [...] (MC, 2007:7)

Como ações e estratégia de investimentos, foi estabelecido o Programa Saneamento para Todos, que visa o financiamento de operações de crédito com recursos do FGTS e do FAT para execução de ações de saneamento básico. Estados e municípios poderão solicitar financiamento para obras de implantação e ampliação de redes de abastecimento de água, esgotamento sanitário, manejo de resíduos sólidos, águas pluviais e resíduos da construção, saneamento integrado, além da preservação e recuperação de mananciais e elaboração de estudos e projetos que tenham o objetivo de qualificar a gestão da prestação de serviços (Brasil, 2008).

Neste contexto, o Programa Saneamento para Todos destinou, em 2008, R \$ 449,3 milhões para financiar 100 projetos de abastecimento de água; $\mathrm{R} \$ 524,5$ milhões para 85 projetos de esgotamento sanitário; $\mathrm{R} \$ 132,1$ milhões para 23 projetos de saneamento integrado; $R \$ 654,1$ milhões para 53 projetos de drenagem; $\mathrm{R} \$ 307,4$ milhões para 97 projetos de resíduos sólidos; e R\$ 154,8 milhões para 175 propostas de estudos e projetos. A região Sudeste foi a que recebeu mais financiamentos, cerca de $\mathrm{R} \$ 1,08$ bilhão (Brasil, 2008).

Além desses recursos, de acordo com o Ministério das Cidades (2007), desde 2007 estão sendo disponibilizados mais de $\mathrm{R} \$ 40$ bilhões para investimento em saneamento até o ano 2012, como pode ser visto na tabela 2 . 
Tabela 2

Fontes de recursos para saneamento básico 2007-12

\begin{tabular}{llc}
\hline Fonte & Prioridades de investimento & Investimento \\
\hline & $\begin{array}{l}\text { Saneamento integrado em favelas e palafitas (PPI) } \\
\text { Água, esgoto, destinação final de lixo e drenagem urbana em cidades de } \\
\text { grande e médio porte, incluindo desenvolvimento institucional (PPI) }\end{array}$ & 4 \\
OGU & $\begin{array}{l}\text { Água, esgoto, destinação final de lixo e drenagem urbana em cidades } \\
\text { de até 50 mil habitantes (Funasa) } \\
\text { Subtotal }\end{array}$ & 4 \\
\hline & $\begin{array}{l}\text { Financiamento a estados, municípios e prestadores públicos de serviços } \\
\text { de saneamento }\end{array}$ & 12 \\
\hline FGTS / FAT & $\begin{array}{l}\text { Financiamento a prestadores privados e operações de mercado } \\
\text { Contrapartida de estados, municípios e prestadores }\end{array}$ & 8 \\
\hline TOTAL & Subtotal & 20 \\
\hline
\end{tabular}

Fonte: Ministério das Cidades - Secretaria Nacional de Saneamento Ambiental (2008). *(R\$ bilhões).

Deste montante, foi definido como uma das prioridades pela Fundação Nacional da Saúde (Funasa) - em conjunto com o Ministério das Cidades e da Integração Nacional, o saneamento em municípios com população total de até 50 mil habitantes (Funasa, 2008). Em 2007, o montante de recursos investidos em saneamento básico - total entre recursos reembolsáveis e não reembolsáveis - foi de, aproximadamente, $\mathrm{R} \$ 10,4$ bilhões, sendo $69,73 \%$ oriundos do OGU e 30,26\% de financiamentos (MC, 2007).

No âmbito das empresas privadas, segundo os dados da Associação Brasileira das Concessionárias Privadas de Serviços Públicos de Água e Esgoto (Abcon, 2008a), o setor privado atende 9,6\% dos serviços públicos de água e esgoto da população urbana no Brasil, com 198 concessões em 202 municípios (Abcon, 2008b). Ainda conforme dados consolidados divulgados pela Abcon (2008b), estão previstos investimentos do setor privado em saneamento da ordem de R\$ 1,4 bilhão, no período de 2008 a 2012.

A soma de todos estes recursos poderá ser capaz de alterar substancialmente o cenário urbano-ambiental brasileiro. Espera-se que mais 24,5 milhões de brasileiros passem a ter água encanada, 25,4 milhões, coleta e tratamento de esgotos e 31,1 milhões, coleta e destinação adequadas de resíduos sólidos 
(Assemae, 2007). Este incremento fará o país alcançar significativo avanço na meta comprometida com a Organização das Nações Unidas (ONU) em reduzir pela metade a proporção de pessoas sem acesso ao abastecimento de água e ao esgotamento sanitário até o ano de 2015, tendo por base o ano de 1990 (Pnud, 2008).

No entanto, ainda em relação ao tratamento de esgoto, a probabilidade de o Brasil cumprir este objetivo, o sétimo dos Objetivos de Desenvolvimento do Milênio (ODM), é de apenas 30\% (PMSS, 2007). O acesso a esses recursos exigirá ampliação do planejamento dos sistemas de forma integrada, por meio de projetos que primem pela qualidade e estejam pautados nos Planos Municipais de Saneamento Básico.

Não somente a escassez de recursos e a falta de financiamento foram as causas do atraso no desenvolvimento do setor de saneamento no Brasil (BNDES, 2008b). Esse déficit se deve, além dos problemas relacionados à restrição de recursos financeiros, à falta de avaliação dos custos ambientais, econômicos e sociais relacionados à implantação, operação e manutenção dos investimentos, ou seja, por não levar em consideração a sustentabilidade dos mesmos. Segundo Klevas, Streimikiene e Kleviene (2009), a cultura do desenvolvimento econômico é ainda resistente em considerar o conceito de desenvolvimento sustentável no processo de tomada de decisão.

Conforme os dados consolidados do Snis (2007), em 2006, dos R $\$ 4,5$ bilhões investidos em saneamento, $49 \%$ foram realizados com recursos próprios das organizações de saneamento; $29 \%$ foram realizados com recursos onerosos (financiamentos retornáveis por meio de amortizações, juros e outros encargos); e 10\% foram realizados com recursos não onerosos (investimentos realizados com recursos não reembolsáveis, que não oneram o serviço da dívida). Todavia, em muitos desses investimentos, não foram considerados os custos de operação e manutenção dos sistemas, sendo considerados somente os seus custos de implantação, e isso faz com que "as despesas totais de tais prestadores de serviços deixem de contemplar um elemento de custo importante, necessário à reposição dos investimentos" (Snis, 2007:113).

As leis que agora regem os serviços públicos de saneamento básico preveem, entre outros princípios, que os investimentos devam alcançar a eficiência e sustentabilidade econômica. Esse desafio, a ser enfrentado pelos municípios brasileiros, demanda atuação consistente e multidisciplinar para que seja superado de forma sustentável (BNDES, 2008a). Segundo Zuffo (1998:5), "com a implantação no País de gestão dos recursos hídricos, considerando as bacias hidrográficas como unidades de gerenciamento, haverá grande ne- 
cessidade de ferramentas que venham a auxiliar os órgãos administradores a realizar tal atividade".

De acordo com os objetivos propostos pela Assemae, existe a necessidade de se desenvolver o saneamento no Brasil, trazendo contribuições técnicas que possam auxiliar esse desenvolvimento, baseadas "no desenvolvimento e divulgação de pesquisas tecnológicas, incentivando programas de melhoria da qualidade do saneamento ambiental" (Assemae, 2006).

\section{Novas estratégias de gestão}

As políticas públicas voltadas para a melhoria das condições de saneamento básico das comunidades são eficazes para diminuir a mortalidade infantil pós-neonatal, período este em que os óbitos ocorrem devido principalmente a doenças relacionadas às condições do ambiente em que se vive. Esse fato confirma que o aumento da cobertura populacional por sistemas de esgotamento sanitário pode contribuir para reduzir ainda mais a mortalidade infantil no Brasil (Holcman, Latorre e Santos, 2004).

Neste contexto, os efeitos positivos do saneamento no crescimento econômico e na redução da pobreza são evidentes. Segundo um estudo da Organização Mundial da Saúde, cada dólar investido na melhoria do saneamento para o alcance dos Objetivos de Desenvolvimento do Milênio gera, em média, um benefício econômico de US\$12 (Prüss-Üstün et al., 2008).

Desta evidência, novas formas de investimentos podem ser elaboradas, como estratégias diferenciadas para a realização do investimento no setor de saneamento. Como exemplo, cita-se aqui o projeto "Água Limpa", implantado em 31 de maio de 2005 e coordenado pela Secretaria de Energia, Recursos Hídricos e Saneamento (SERHS) do estado de São Paulo. Esse projeto recebe verbas provenientes do orçamento do setor da saúde e tem por objetivo recuperar a qualidade das águas, melhorando a qualidade de vida dos habitantes dos municípios, bem como os indicadores de saúde pública e desenvolvimento da cidade, com o investimento e a implantação de obras de tratamento de efluentes urbanos, em municípios de até 30 mil habitantes, que não são atendidos pela Sabesp.

O engenheiro Carlos Eduardo Alencastre, secretário executivo do Comitê da Bacia Hidrográfica do Pardo (CBH-Pardo), destacou que a manutenção dos critérios que priorizam o saneamento básico vem ao encontro do que preconiza o plano para a universalização dos serviços de coleta e tratamento de 
esgotos nos municípios da área do CBH-Pardo (27 cidades), em grande parte por meio dos recursos advindos deste projeto.

O projeto "Água Limpa" só disponibiliza recursos na fase de instalação do sistema, ficando a operação e manutenção a cargo das prefeituras. Dessa forma, há uma necessidade de garantir, através de uma justa cobrança tarifária, a continuidade dos serviços, que sejam capazes de cobrir os custos de operação e manutenção do sistema, além de gerar um excedente para retornar os valores dos financiamentos, quando for o caso.

O Prodes, da Agência Nacional de Águas (ANA), do Ministério do Meio Ambiente, em Brasília, também é conhecido como "programa de compra de esgoto tratado", e pode ser considerado uma iniciativa inovadora, uma vez que não financia obras ou equipamentos, mas paga pelos resultados alcançados pelo esgoto efetivamente tratado.

Segundo os entrevistados na ANA, muitas das estações financiadas pelo Prodes foram projetadas com combinação de processos anaeróbios e aeróbios no tratamento e levam em consideração a sustentabilidade do empreendimento com base em indicadores tecnológicos, tais como: qualificação da mão de obra, nível cultural ou outros, e outros indicadores, tais como o Índice de Desenvolvimento Humano (IDH), do Programa das Nações Unidas para o Desenvolvimento.

Outros modelos de gestão foram analisados por Justo (2004), que comparou a gestão pública com a privada, concluindo que, com base na comparação entre dois casos nacionais estudados de concessão e um de gestão pública, a universalização dos serviços de saneamento básico no Brasil poderia ser alcançada por meio da tarifa cobrada pelos serviços. Para o caso das empresas públicas, tornar-se-ia necessária a redução, por meio de renegociação de contratos das empresas do setor público com o setor privado, do total de dívidas a curto prazo além de diminuição dos índices de perdas nos serviços. No caso das empresas privadas, percebeu-se que todas as vantagens, como o aumento na lucratividade, foram apropriadas pela empresa, não sendo revertidas em novos investimentos.

\section{Considerações finais}

Sistemas de abastecimento de água e de esgotamento sanitário proporcionam benefícios gerais para a saúde da população, seguindo duas vias: mediante efeitos diretos e indiretos, resultantes, primordialmente, do nível de desenvolvimento da localidade atendida. Os efeitos das intervenções de saneamento 
são geralmente positivos, por se constituírem em um serviço que assegura melhoria e bem-estar da população (Vanderslice e Briscoe, 1995).

Todavia, os investimentos em saneamento devem atender a requisitos técnicos, ambientais, sociais e econômicos, de forma a se trabalhar o conceito de desenvolvimento sustentável, de preservação e conservação do meio ambiente e particularmente dos recursos hídricos, refletindo diretamente no planejamento das ações de saneamento.

Historicamente, o investimento em saneamento ocorreu de forma pontual no Brasil, sendo predominantemente realizado pelo setor público. Além disso, soma-se o fato de que a falta de uma definição clara das responsabilidades peculiares à União, estados, Distrito Federal e municípios tornou difusa a aplicação dos recursos em saneamento, não respeitando uma visão de planejamento global dos investimentos. O setor também foi marcado pela baixa capacidade de endividamento das organizações estatais e a pequena participação do setor privado.

Neste início de século, com a retomada dos investimentos, torna-se necessário, além da melhoria na governança das organizações do setor, um planejamento consistente dos recursos a serem investidos para que o quadro até então verificado possa ser revertido em uma melhor qualidade do setor no país.

\section{Referências}

ABCON (ASSOCIAÇÃO BRASILEIRA DAS CONCESSIONÁRIAS PRIVADAS DE SERVIÇOS PÚBLICOS DE ÁGUA E ESGOTO). Panorama da participação do setor privado. Disponível em: <www.abcon.com.br/index.php/379>. Acesso em: 18 dez. 2008a.

. Concessões privadas em operação. Disponível em: <www.abcon.com.br/xls/2. xls >. Acesso em: 18 dez. 2008b.

AESBE (ASSOCIAÇÃO DAS EMPRESAS DE SANEAMENTO BÁSICO ESTADUAIS). Financiamento de investimentos em saneamento básico: medidas sugeridas para expansão sustentável e modernizadora. 2006. Disponível em: <www.aesbe.org. $\mathrm{br} / \mathrm{aesbe} / \mathrm{pages} /$ documento/exibirAnexo.do?tipo $=$ documentos\&arquivo $=16 . \mathrm{pdf}>$. Acesso em: 2 out. 2008.

ANA (AGÊNCIA NACIONAL DE ÁGUAS). O que é o Prodes. Disponível em: < www. ana.gov.br/prodes/prodes.asp>. Acesso em: 1ํo jul. 2008. 
ASSEMAE (ASSOCIAÇÃO NACIONAL DOS SERVIÇOS MUNICIPAIS DE SANEAMENTO). A visão da Assemae sobre os principais aspectos conjunturais que interessam ao saneamento ambiental nos municípios brasileiros. Disponível em: <www.assemae. org.br/ibam.htm>. Acesso em: 27 nov. 2006.

. A visão da Assemae sobre a promulgação da Lei 11.445/07. Disponível em: <www.assemae.org.br/visaoassemae.htm >. Acesso em: 10 abr. 2007.

BNDES (BANCO NACIONAL DE DESENVOLVIMENTO). A infraestrutura urbana. Disponível em: <www.bndes.gov.br/conhecimento/livro_setorial/setorial12.pdf >. Acesso em: 10 dez. 2008a.

. Apoio ao setor de saneamento. Disponível em: <www.bndes.gov.br/conhecimento/bnset/set2804.pdf>. Acesso em: 10 dez. 2008b.

BRASIL. Constituição Federativa do Brasil: emendas constitucionais ns. 1 a 48 devidamente incorporadas. 3. ed. rev. e ampl. Barueri: Manole, 2006.

. Pacto pelo saneamento básico: Plano Nacional em Saneamento Básico. Disponível em: <www.cidades.gov.br/secretarias-nacionais/saneamento-ambiental/>. Acesso em: 18 dez. 2008.

CONAMA (CONSELHO NACIONAL DO MEIO AMBIENTE). Resolução Conama $n^{\circ}$ 357, de 17 de março de 2005. Dispõe sobre a classificação dos corpos de água e diretrizes ambientais para o seu enquadramento, bem como estabelece as condições e padrões de lançamento de efluentes, e dá outras providências. Brasília: MMA, 2005.

CONAMA (CONSELHO NACIONAL DO MEIO AMBIENTE). Resolução Conama $n^{\circ}$ 397, de 3 de abril de 2008. Altera o inciso II do $\S 4^{\circ}$ e a Tabela X do § 5ㅇ, ambos do art. 34 da Resolução do Conselho Nacional do Meio Ambiente - Conama nº 357, de 2005, que dispõe sobre a classificação dos corpos de água e diretrizes ambientais para o seu enquadramento, bem como estabelece as condições e padrões de lançamento de efluentes. Brasília: MMA, 2008.

COOPER, Donald R.; SCHINDLER, Pamela S. Métodos de pesquisa em administração. 7. ed. Porto Alegre: Bookman, 2003.

FUNASA (FUNDAÇÃO NACIONAL DA SAÚDE). Programa de Aceleração do Crescimento (PAC). Disponível em: <www.funasa.gov.br/index_III.htm>. Acesso em: 27 jun. 2008.

GIL, A.C. Como elaborar projetos de pesquisa. 2. ed. São Paulo: Atlas, 1989.

HOLCMAN, N.M.; LATORRE, M.R.D.O.; SANTOS, J.L.F. Evolução da mortalidade infantil na região metropolitana de São Paulo, 1980-2000. Revista Saúde Pública, v. 38, n. 2, p. 180-186, 2004. 
IBGE (INSTITUTO BRASILEIRO DE GEOGRAFIA E ESTATÍSTICA). Pesquisa nacional de saneamento básico. 2000. Disponível em: <www.ibge.com.br/>. Acesso em: 7 set. 2007.

JUSTO, M.C.D. de M. Financiamento do saneamento básico no Brasil: uma análise comparativa da gestão pública e privada. 2004. 165 f. Dissertação (mestrado em desenvolvimento econômico, espaço e meio ambiente) - Instituto de Economia, Universidade Estadual de Campinas, Campinas, 2004.

KLEVAS, V.; STREIMIKIENE, D.; KLEVIENE, A. Sustainability assessment of the energy projects implementation in regional scale. Renewable and Sustainable Energy Reviews, v. 13, p. 155-166, 2009.

MC (MINISTÉRIO DAS CIDADES). Gasto público em saneamento básico: relatório de aplicações de 2007. Disponível em: <www.cidades.gov.br/secretarias-nacionais/saneamento-ambiental/> . Acesso em: $18 \mathrm{dez} .2008$.

PMSS (PROGRAMA DE MODERNIZAÇÃO DO SETOR DE SANEAMENTO). Estudo sobre déficit e metas do milênio: estudo sobre a qualificação do déficit em saneamento básico e metas do milênio. 2007. Apresentação. Disponível em: <www.pmss.gov.br/ pmss/PaginaCarrega.php?EWRErterterTERTer=229> . Acesso em: 15 dez. 2008.

PNUD (PROGRAMA DAS NAÇÕES UNIDAS PARA O DESENVOLVIMENTO). Brasil dificilmente alcançará ODM de esgoto. Disponível em: <www.pnud.org.br/odm/>. Acesso em: 12 nov. 2008.

PROSAB (PROGRAMA DE PESQUISAS EM SANEAMENTO BÁSICO). Reúso das águas de esgoto sanitário, inclusive desenvolvimento de tecnologia de tratamento para esse fim. Rio de Janeiro: Abes, 2006.

PRÜSS-ÜSTÜN, A. et al. Safer water, better health: costs, benefits and sustainability of interventions to protect and promote health. Geneva: World Health Organization, 2008.

SAIANI, C.C.S. Restrições à expansão dos investimentos em saneamento básico no Brasil: déficit de acesso e desempenho dos prestadores. 2007. 315 f. Dissertação (mestrado em economia aplicada) - Faculdade de Economia, Administração e Contabilidade de Ribeirão Preto, Universidade de São Paulo, Ribeirão Preto, 2007.

SNIS (SISTEMA NACIONAL DE INFORMAÇÕES EM SANEAMENTO). Disponível em: <www.snis.gov.br/>. Acesso em: 13 mar. 2007.

SOARES, S.R.A.; BERNARDES, R.S.; CORDEIRO NETTO, O.M. Relações entre saneamento, saúde pública e meio ambiente: elementos para formulação de um modelo de planejamento em saneamento. Cadernos de Saúde Pública, Rio de Janeiro, v. 18, p. 1713-1724, 2002. 
SOUZA, C.M.N.; FREITAS, C.M.; MORAES, L.R.S. Discursos sobre a relação saneamento-saúde-ambiente na legislação: uma análise de conceitos e diretrizes. Engenharia Sanitária e Ambiental, v. 12, n. 4, p. 371-379, 2007.

TONETO JUNIOR, R. A situação atual do saneamento básico no Brasil: problemas e perspectivas. 2004. 324 f. Tese (livre-docência em economia) — Faculdade de Economia, Administração e Contabilidade, Universidade de São Paulo, São Paulo, 2004.

TUROLLA, F.A. Política de saneamento básico: avanços recentes e opções futuras de políticas públicas. Brasília: Ipea, 2002.

UNDP (UNITED NATIONS DEVELOPMENT POPULATION). Drinking water standards and health advisories. Washington, 2000.

VANDERSLICE, J.; BRISCOE, J. Environmental interventions in developing countries: interactions and their implications. American Journal of Epidemiology, v. 141, p. 135-144, 1995.

ZUFFO, A.C. Seleção e aplicação de métodos multicriteriais ao planejamento ambiental de recursos hídricos. 1998. $286 \mathrm{f}$. Tese (doutorado em engenharia civil) — Escola de Engenharia de São Carlos, Universidade de São Paulo, São Carlos, 1998. 